\title{
Performance of Optical Amplifiers With Regard To The Power Penalties of a DWDM XGS-PON Network Environment
}

Desempeño de amplificadores ópticos con respecto a las penalidades de potencia de un entorno de red DWDM XGS-PON

Desempenho de amplificadores ópticos relativos às penalidades de energia de um ambiente de rede DWDM XGS-PON

\author{
Ana Maria Marulanda Pungo ${ }^{1}$ \\ Paola Juliana Paredes Cerón ${ }^{2}$ \\ Gustavo Adolfo Gómez Agredo
}

Received: Febreruary $1^{\text {St }}, 2020$

Accepted: April $5^{\text {th }}, 2020$

Available: May $4^{\text {th }}, 2020$

How to cite this article:

A.M. Marulanda Pungo, P. J. Paredes Cerón, G. A. Gómez Agredo, "Performance of Optical Amplifiers With Regard To The Power Penalties Of A Dwdm Xgs-Pon Network Environment," Revista Ingeniería Solidaria, vol. 16, no. 2, 2020. doi: https://doi.org/10.16925/2357-6014.2020.02.04

Artículo de investigación. https://doi.org/10.16925/2357-6014.2020.02.04

1 University of Cauca, Popayán, Colombia. Faculty of Electronic Engineering and Telecommunications, Department of Telecommunications.

University of Cauca, Department of Telecommunications, Member of the Research Group in New Technologies in Telecommunications -GNTT

E-mail: anamarulan@unicauca.edu.co ORCID: https://orcid.org/0000-0003-2367-1440

2 University of Cauca, Popayán, Colombia. Faculty of Electronic Engineering and Telecommunications, Department of Telecommunications.

University of Cauca, Department of Telecommunications, Member of the Research Group in New Technologies in Telecommunications -GNTT

E-mail: paolapa@unicauca.edu.co

ORCID: https://orcid.org/0000-0002-9189-2942

3 University of Cauca, Popayán, Colombia. Electronics and Telecommunications Engineer, University of Cauca, Colombia.

Member of the Research Group in New Technologies in Telecommunications -GNTT

E-mail: gtgomez@unicauca.edu.co

ORCID: https://orcid.org/0000-0002-3413-562X 


\section{Abstract}

Introduction: This article is the product of the research "Simulation level performance analysis of optical amplifiers for a DWDM XGS-PON network environment", supported by the Research Group in New Technologies in Telecommunications (GNTT) of the University of Cauca during 2019.

Problem: For the implementation of XGS-PON optical network architectures, amplification processes are required. These generate power penalties that lead to the presence of non-linear phenomena, significantly degrading network performance.

Objective: To analyze the performance of a DWDM / XGS-PON network architecture, respecting the power penalties generated by implementing different types of optical amplifiers in different amplification modes.

Methodology: Compilation of relevant bibliography on long-range network architectures with symmetric speeds of $10 \mathrm{Gbps}$.

Results: Not working in the ideal region of amplification affects the performance of a DWDM XGS-PON network, generating a migration of a linear to non-linear propagation regime, due to the presence of power penalties such as FWM.

Conclusion: With this investigation it is possible to determine which amplifier should be used according to the needs of the optical network, evaluating the different alternatives available in the market, depending on the cost, configuration and performance of the system.

Originality: A new research is carried out for the performance of DWDM XGS-PON state-of-the-art network architectures, regarding the incidence of non-linear propagation phenomena.

Restrictions: In some cases, the simulation tool requires a high consumption of machine resources and processing time.

Keywords: optical amplifiers, network architectures, DWDM, XGS-PON, power penalties.

\section{Resumen}

Introducción: Artículo producto de la investigación "Análisis del desempeño a nivel de simulación, de amplificadores ópticos para un entorno de red DWDM XGS-PON", soportado por el Grupo de Investigación de Nuevas Tecnologías en Telecomunicaciones (GNTT) de la universidad del Cauca durante el 2019.

Problema: Para la implementación de las arquitecturas de red ópticas XGS-PON se requieren procesos de amplificación, los cuales generan penalidades de potencia que acarrean la presencia de fenómenos de tipo no lineal, degradando significativamente el desempeño de la red.

Objetivo: Analizar el desempeño de una arquitectura de red DWDM XGS-PON, con respecto a las penalidades de potencia generadas al implementar diferentes tipos de amplificadores ópticos en diferentes modos de amplificación.

Metodología: Recopilación de bibliografía relevante sobre arquitecturas de redes ópticas de largo alcance con velocidades simétricas de $10 \mathrm{Gbps}$.

Resultados: No trabajar en la región ideal de amplificación, afecta el desempeño de una red DWDM XGS-PON, generando una migración de un régimen de propagación lineal a no lineal, debido a la presencia de penalidades de potencia como FWM.

Conclusión: Con esta investigación es posible determinar cuál es el amplificador que se debe utilizar según las necesidades de la red óptica, evaluando las alternativas disponibles en el mercado, en función del costo, configuración y desempeño del sistema. 
Originalidad: Se realiza una investigación novedosa para el desempeño de arquitecturas de red de última generación DWDM XGS-PON, con respecto a la incidencia de fenómenos de propagación no lineales.

Limitaciones: En algunos casos, la herramienta de simulación requiere un alto consumo de recursos de máquina y tiempo de procesamiento.

Palabras clave: amplificadores ópticos, arquitecturas de Red, DWDM, XGS-PON, penalidades de potencia.

\section{Resumo}

Introdução: produto do artigo da pesquisa "Análise de desempenho no nível de simulação, de amplificadores ópticos para um ambiente de rede DWDM XGS-PON", apoiada pelo Grupo de Pesquisa em Novas Tecnologias em Telecomunicações (GNTT) da Universidade de Cauca em 2019.

Problema: Para a implementação de arquiteturas de rede óptica XGS-PON, são necessários processos de amplificação, que geram penalidades de energia que levam à presença de fenômenos não lineares, degradando significativamente o desempenho da rede.

Objetivo: Analisar o desempenho de uma arquitetura de rede DWDM / XGS-PON, respeitando as penalidades de energia geradas pela implementação de diferentes tipos de amplificadores ópticos em diferentes modos de amplificação.

Metodologia: Compilação de bibliografia relevante sobre arquiteturas de rede de longo alcance com velocidades simétricas de $10 \mathrm{Gbps}$.

Resultados: 0 não trabalho na região ideal de amplificação afeta o desempenho de uma rede DWDM XGS-PON, gerando a migração de um regime de propagação linear para não linear, devido à presença de penalidades de energia, como o FWM.

Conclusão: Com esta investigação, é possível determinar qual amplificador deve ser utilizado de acordo com as necessidades da rede óptica, avaliando as diferentes alternativas disponíveis no mercado, dependendo do custo, configuração e desempenho do sistema.

Originalidade: Uma nova pesquisa é realizada para o desempenho das arquiteturas de rede de ponta do DWDM XGS-PON, em relação à incidência de fenômenos de propagação não linear.

Restrições: Em alguns casos, a ferramenta de simulação requer um alto consumo de recursos da máquina e tempo de processamento.

Palavras-chave: amplificadores ópticos, arquiteturas de rede, DWDM, XGS-PON, multas de energia.

\section{INTRODUCTION}

At present, one of the most implemented technologies for the transmission and support of information, are the optical systems; However, these present some drawbacks focused on the power elements (power penalties), presence of linear and non-linear phenomena, and costs of displaying network architectures. Although the optical fiber has low losses, some type of amplification is required for very large distances, these devices being one of the most expensive in the system. 
The behavior of the optical amplification, is determined with respect to factors that produce effects in the system. These variables can be internal to the amplifier such as: wavelength, power and pumping source, among others, and external to the amplifier, which are the network load level (throughput), the proximity of the channels and the amplification mode, which can occur from three points of view i) booster ii) pre-amplification and iii) in line.

This article focuses its study on observing the effects that occur at the simulation level, in a DWDM XGS-PON network architecture, by implementing different optical amplifiers by manipulating their variables and their configuration modes, in order to determine if the presence of power penalties manages to significantly degrade the performance of the optical system.

\section{LITERATURE REVIEW}

This section presents investigations of previous works that were taken as a theoretical reference for topics related to DWDM XGS-PON optical communications systems, power penalties and different types of amplification.

Zaman, Iqbal and Isha [1], performed an analysis of the dense wavelength division multiplexing system (DWDM) using the erbium doped fiber amplifier (EDFA) in the $C$ band, which works at $1530 \mathrm{~nm}-1565 \mathrm{~nm}$. For optimal results in the parameters of gain, noise, gain acceleration and bit error rate (BER), variables such as input channel power, channel spacing, EDFA length, pump power and erbium concentration were adjusted. In addition, direct and indirect pumping methods were studied. The result of the simulations and analysis of the results, were carried out by means of an optical simulation software.

Gómez and Grijalba [2] suggested the types of linear and non-linear effects, which contribute to the most significant limitations in fiber optic systems, such as attenuation, noise, dispersion, and second-order phenomena such as four-wave mix (FWM), auto phase modulation (SPM) and cross phase modulation (XPM). Likewise, the optical monitoring parameters defined by the international telecommunications union were detailed in the ITU-T G.697 standard [3], and the modulation formats that have received the greatest interest within the context of optical communications were selected to subsequently, evaluate the performance at the physical level.

Ramaswami, Sivajaran and Sasaki [4] in chapters 2-5 covered the components and aspects of the transmission technology of optical networks, which includes a detailed investigation into the effects of power penalties, which is an important factor in the design of power systems with long distance high bit rates. This phenomenon 
occurs with the increase in signal strength in the receiver to achieve the same BER performance or signal-to-noise ratio (SNR), which has an ideal system, with the aim of compensating for different degradations that may occur in the system.

Singh and Kaler [5], cover the investigation of a 10 Gbps 16, 32 and 64 channel wavelength division multiplexing (WDM) system, with SOA, EDFA, and RAMAN amplifiers, in order to compare performance with respect to transmission distance and dispersion with and without nonlinearities. With this project, it was verified that for low dispersion values and fewer channels, better results are obtained with SOA, however, increasing the number of channels causes degradation. Whereas, if the dispersion and the number of channels increases, EDFA shows better results than SOA based on the BER and the output power, but a non-uniform gain spectrum is presented. As for RAMAN, this provides low output power compared to any other existing amplifier and can offer a better result for longer wavelengths.

Torres [6], makes a comparison of the spectral characteristics and operating regimes that can be obtained with fiber optic laser systems using two types of optical amplifiers: erbium doped fiber amplifier (EDFA) and semiconductor optical amplifier (SOA). In general, ITU-T G.661 [7] and G.663 [8] standards establish that the first one is based on erbium doped fiber and a pumping source that can be in the same direction (co-propagation) of the input signal, in the opposite direction (counter-propagation) or bidirectional, with a pump co-propagated and counter-propagated simultaneously; the second corresponds to an opto-electronic component that works like a laser, regenerating signals at different wavelengths simultaneously and with a shorter response time compared to fiber optic amplifiers (OFA).

Castro [9], studies the basic theoretical foundations with respect to a DWDM network when Raman configurations with dispersion compensation fiber (DCF) are used, through the review of linear effects such as noise, loss, chromatic dispersion and polarization mode dispersion (PMD) and non-linear effects, such as auto phase modulation, cross phase modulation and four wave mixing, compared to optical monitoring parameters (OPM). ITU-T G.665 [10] recommendation, establishes two types of Raman fiber amplifier (RFA), which are classified according to their design: discrete or grouped Raman amplifier (LRA) and distributed Raman amplifier (DRA). In the case of distributed ones, the same fiber that is used for signal transmission is also used for amplification, while discrete ones achieve the amplification effect thanks to a shorter fiber fragment and all the physical elements that are inside the device.

Putrina, Olonkis, Bobrovs and Ivanovs [11], highlight that many factors can severely affect the performance of an optical amplifier, but the most important of these is the power of the input signal, which can be varied by changing the position of an 
amplifier in the optical link. According to ITU-T G.662 [12], there are three possible amplification modes: the first refers to the power amplifier or booster (BA), used after the transmitter block and before the main fiber; the pre-amplifier (PA), is a low noise device that is placed immediately before the receiver and the line amplifier (LA), Iocated between the fiber optic sections (spans), is used in links of more than $150 \mathrm{~km}$ in case the signals weaken over long distances.

Sharif, Ngah, Ahmad, Khairi, Manaf and Tarsono [13] evaluate the performance of the XGS-PON and GPON network architectures by coexisting in the same distribution of optic network (ODN) of fiber to home (FTTH), in terms of measurements of ODN link loss and operational wavelengths, considering that the ITU-T G.9807.1 [14] recommendation describes that XGS-PON operates through a point-to-multipoint optical access infrastructure at a nominal data rate of $10 \mathrm{Gbps}$ both downstream and upstream, and this network architecture can operate in the same ODN and in the same wavelengths as an existing XG-PON system or operate in GPON wavelengths.

\section{MATERIALS AND METHODS}

A description of the OptSim simulation tool is presented, which was taken into account to propose a methodology that allows for the realization of this research.

\subsection{OptSim}

OptSim is a RSoft program acquired by Synopsys, used for the design and simulation of optical communication systems in terms of signal propagation level, which includes: coherent optical communication systems, advanced modulation formats, DWDM systems with optical amplification (either SOA, EDFA, RFA).

This tool has two simulation techniques; namely the spectral propagation technique (SPT) and variable bandwidth technique (VBS), found in Figure 1. SPT is in the spectrum domain, which means the optical signals propagate as power spectra considering noise and the respective losses. In VBS, the signals are propagated as samples in the time domain over a variable bandwidth, being a useful technique to simulate, in addition to fiber losses, linear and non-linear effects. 


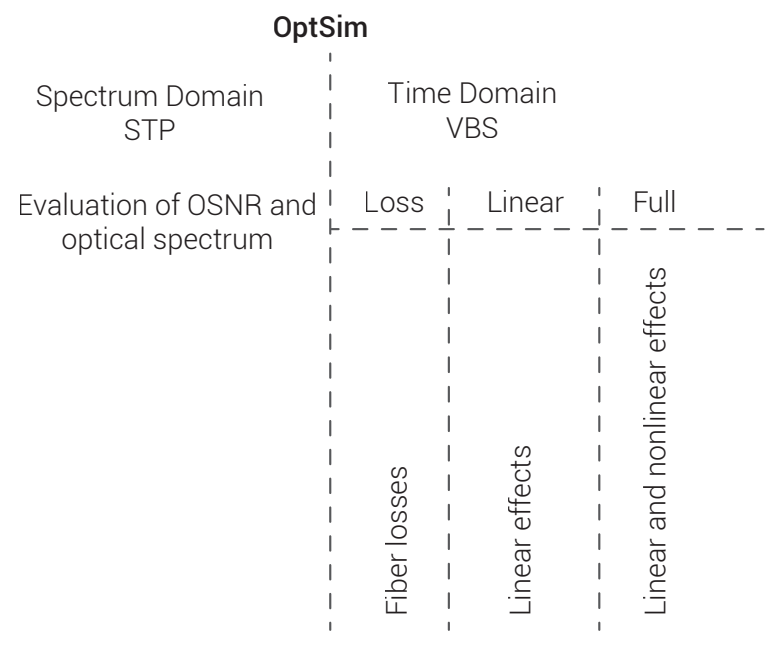

Figure 1. OptSim simulation techniques

Source: SYNOPSYS [15]

\subsection{Methodology}

The research methodology chosen for the development of the work is a cascade model composed of five phases, which occur one after the other from the fulfillment of the previous one, as shown in Figure 2. The first phase is information gathering, which aims to establish the functional requirements of the project; Then, the planning phase, in which the project is divided into small parts to be carried out more easily or separately; Subsequently, the modeling phase, which consists in designing the solution that satisfies the problem; Next, the construction phase, in which the elaborated solution is implemented and performance tests are performed; Finally, the delivery phase, in which the project is monitored to ensure that it meets the requirements established in the beginning.

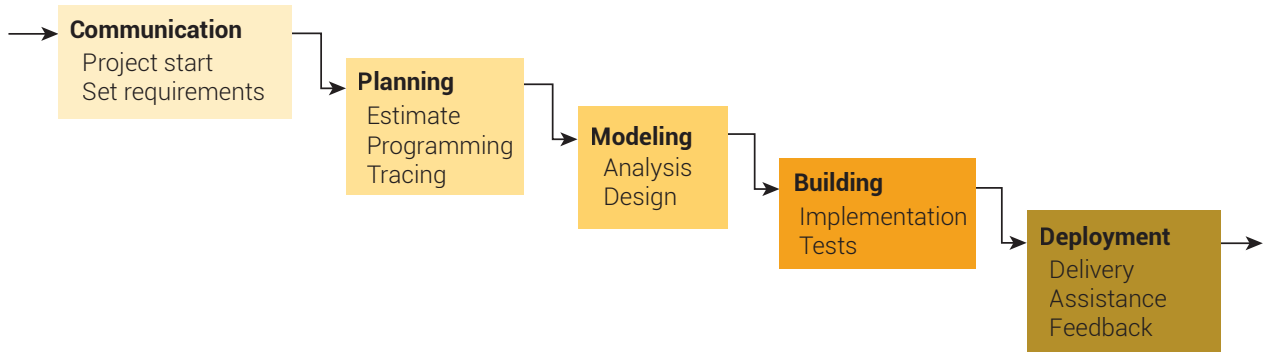

Figure 2. Research methodology

Source: Pressman [16] 
With respect to the simulation methodology that will be used in the development of the project, it is based on [17], and includes the following stages: i) initial specification: analyze the problem to be solved, considering the variables that integrate it and the relationship between them, in the same way the limitations to which the system must adapt ii) model design: develop the representation of the system, taking into account the components and parameters that affect its behavior iii) information collection: identify the data that are relevant to perform an analysis of the results obtained in the simulation iv) model implementation: establish which tools are the most appropriate for the simulation and under what statistics v) validation and analysis: verify that the implemented model complies with the established specifications and if after executing the necessary simulations the results are not the desired ones, the system specifications should be contemplated again vi ) documentation: document the technical aspects of the system vii) implementation: put the model into operation.

In Figure 3, the flow chart with which the simulations of the present investigation will be carried out can be observed.

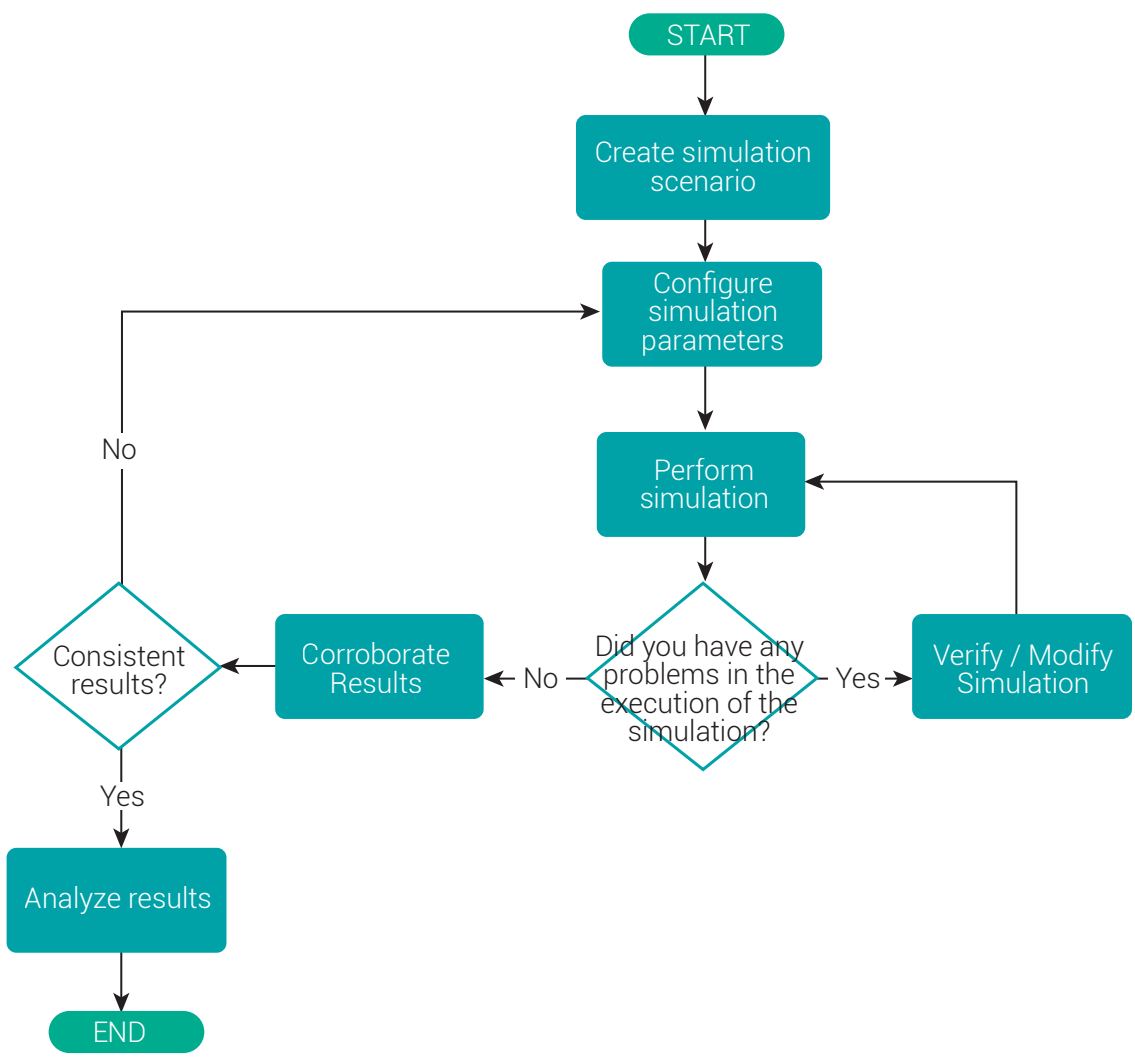

Figure 3. Simulation methodology

Source: own work, based on Villalba and Martínez [18] 


\section{RESULTS}

The simulation scenario in which the network performance will be evaluated corresponds to a DWDM / XGSPON system with the characteristics of Table 1 and $85 \mathrm{~km}$ link distance, where different types of amplification will be used, namely SOA, EDFA and RFA. Each amplifier is configured in booster / pre-amplification / in-line mode and an analysis is performed on the effect produced by the amplification in the system (Kerr phenomena) due to changes in the amplifier's pumping source.

Table 1. General characteristics of the simulation scenario.

\begin{tabular}{cc}
\multicolumn{2}{c}{ GENERAL CHARACTERISTICS } \\
\hline PARAMETERS & VALUES \\
\hline Band & C $(1530-1560 \mathrm{~nm})$ \\
\hline Fiber type & Corning SSMF-28e \\
\hline Attenuation for $1550 \mathrm{~nm}$ & $0.2 \mathrm{~dB} / \mathrm{km}$ \\
\hline Dispersion coefficient for $1550 \mathrm{~nm}$ & $16 \mathrm{ps} / \mathrm{nm} \cdot \mathrm{km}$ \\
\hline Modulation format & RZ-OOK \\
\hline CD Compensation & Ideal \\
\hline Receiver sensitivity & $-28 \mathrm{dBm}$ \\
\hline
\end{tabular}

Source: own work

In order to comply with the XGS-PON standard (10 Gbps speed), 4 channels with $100 \mathrm{GHz}(0.8 \mathrm{~nm})$ spacing are implemented, based on ITU recommendation G.694.1; this with the purpose of reducing the possible effects of adjacent channel interference [19]. To obtain the frequency plan for Table 2, we have considered equation (1), where $\mathrm{n}$ is a positive or negative integer, including 0 , and 193.1 is the reference frequency. From the frequency plan, the lowest frequency $(195.5 \mathrm{THz})$ is chosen as a reference to perform the analysis in the different types of amplification, since, having the highest wavelength, introduces less attenuation, presenting better results compared to the other frequencies.

$100 \mathrm{GHz}: 193.1+\mathrm{n} \times 0.1[\mathrm{THz}]$

For the performance analysis, ITU-T G.698.1 [20] - ITU-T G.Sup39 [21] are taken into account, establishing that you must work with optical monitoring parameters (OPM) BER objectives $\leq 1 e^{-12}$, Q factor $\geq 7.5 \mathrm{~dB}$, and receiver sensitivity $\geq-28 \mathrm{dBm}$ with 2.5 Gbps access. 
Table 2. Frequency plan for 4 channels with $100 \mathrm{GHz}$ spacings.

\begin{tabular}{cccc}
\hline $\begin{array}{c}\text { Channel spacing } \\
\text { [GHz] }\end{array}$ & Number of channels & $\begin{array}{c}\text { Nominal center } \\
\text { frequency [THz] }\end{array}$ & Wavelength [nm] \\
\hline \multirow{3}{*}{100} & Channel 1 & $195.5 ; \mathrm{n}=24$ & 1533.46 \\
\cline { 2 - 4 } & Channel 2 & $195.6 ; \mathrm{n}=25$ & 1532.68 \\
\cline { 2 - 4 } & Channel 3 & $195.7 ; \mathrm{n}=26$ & 1531.89 \\
\cline { 2 - 4 } & Channel 4 & $195.8 ; \mathrm{n}=27$ & 1531.11 \\
\hline
\end{tabular}

Source: own work

In Table 3, Figure 4 (a) and (b), it can be seen that the system without any amplification process (initial conditions) does not meet the target OPMs, which generates a high OSNR, power on reception outside of sensitivity thresholds and a poor error rate. Therefore, it can be deduced that amplification is necessary so that the system does not degrade to the point of not detecting the transmitted channels.

Table 3. Initial conditions of the monitoring parameters.

\begin{tabular}{cccccccc}
\hline $\begin{array}{c}\text { Distance } \\
{[\mathbf{k m}]}\end{array}$ & $\begin{array}{c}\text { Channel } \\
{[\mathrm{THz}]}\end{array}$ & BER & $\begin{array}{c}\mathbf{Q} \text { Factor } \\
{[\mathbf{d B}]}\end{array}$ & $\mathbf{P}_{\mathbf{T x}}[\mathbf{d B m}]$ & $\mathbf{P}_{\mathbf{R x}}[\mathbf{d B m}]$ & $\begin{array}{c}\text { Jitter } \\
{[\mathbf{n s}]}\end{array}$ & $\begin{array}{c}\text { OSNR }_{\text {OUT }} \\
{[\mathbf{d B}]}\end{array}$ \\
\hline 85 & 195.5 & 0.019 & 6.284 & 0 & -34.81 & 0.023 & 48.76 \\
\hline
\end{tabular}

Source: own work

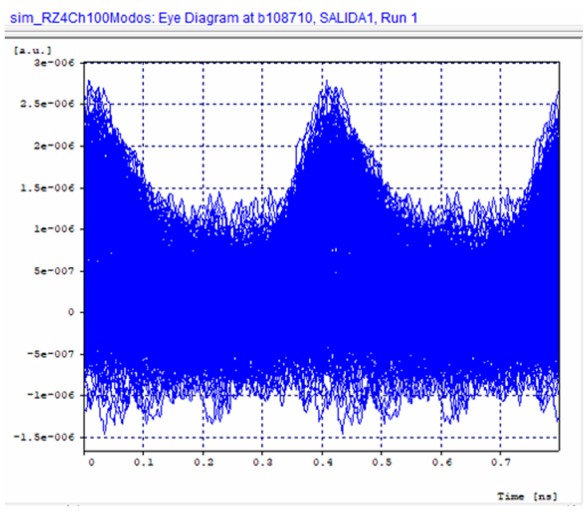

(a)

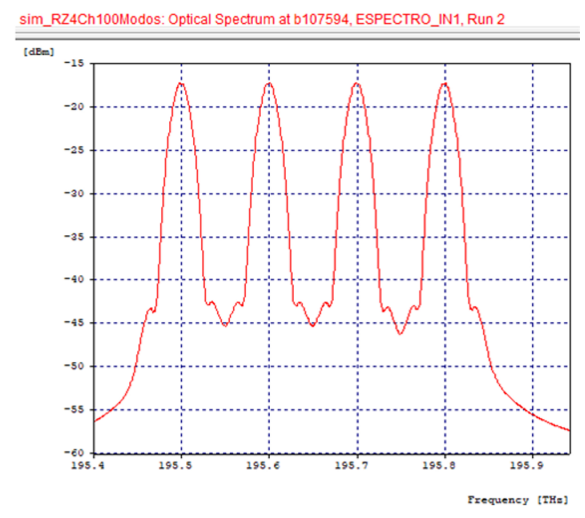

(b)

Figure 4. (a) Eye diagram (b) Optical spectrum propagated in initial conditions. Source: own work 
Figure 5 shows the general simulation scenario with which a comparative analysis of the performance of a DWDM XGS-PON network will be performed when using optical amplifiers, modifying their pumping and configuration parameters, in order to find the ideal region in which the amplifier works in each case. The metrics that are considered refer to the amplifier design parameters available in the market, which are similar to the variables that allow the simulation tool to be configured for each type of amplifier. In addition, the established parameters of said commercially available equipment are taken into account, to verify whether these parameters correspond to the best performance with respect to optical monitoring parameters and in the second instance, regarding the power penalties that are generated due to the incidence of nonlinear phenomena.

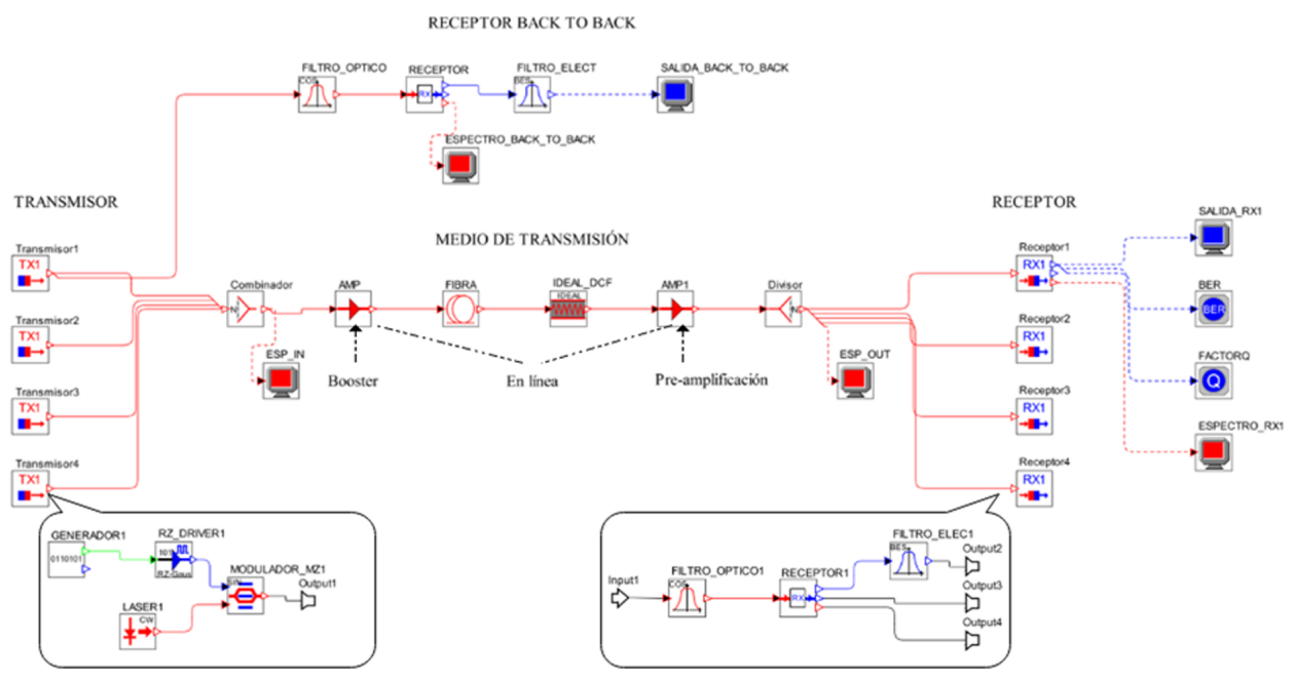

Figure 5. Simulation scheme for $4 \lambda \times 2.5$ Gbps DWDM system.

Source: own work

\subsection{SOA amplifier}

Table 4 shows the physical parameters of the SOA amplifier, defined by the manufacturer Alcatel Thalés Research and Technology, which match the configurable parameters of the SOA component available in OptSim. As for the simulation tool, it allows for the operator to modify most of the parameters. It can be used in systems that are above $10 \mathrm{Gbps}$, offers an output power of up to $10 \mathrm{dBm}$ with input powers ranging from $-25 \mathrm{dBm}$ to $-8 \mathrm{dBm}$ and operates with a gain of $18.5 \mathrm{~dB}$. 
Table 4. SOA parameters.

\begin{tabular}{cc}
\hline & P ARAMETERS \\
\hline Signal wavelength $[\mathrm{nm}]$ & 1540 \\
\hline 3dB Output saturation power $[\mathrm{dBm}]$ & $5 \mathrm{a} 10$ \\
\hline Bias current $(\mathrm{I})[\mathrm{mA}]$ & 150 \\
\hline Amplifier length $(\mathrm{L})[\mu \mathrm{m}]$ & 700 \\
\hline Amplifier width $(\mathrm{W})[\mu \mathrm{m}]$ & 1.5 \\
\hline Amplifier thickness $[\mu \mathrm{m}]$ & 0.15 \\
\hline Confinement factor $(\square)$ & 0.3 \\
\hline Transparency carrier density $(\mathrm{No})\left[\mathrm{m}^{-3}\right]$ & $1 \times 10^{24}$ \\
\hline Material gain constant $\left[\mathrm{cm}{ }^{2}\right]$ & $3 \times 10^{-16}$ \\
\hline Spontaneous carrier lifetime $[\mathrm{ns}]$ & 0.3 \\
\hline Linewidth enhacement factor $\left.^{-1}\right]$ & 5 \\
\hline Material loss $\left[\mathrm{m}^{-1}\right]$ & 1050 \\
\hline Input/output Insertion loss $[\mathrm{dB}]$ & 3 \\
\hline
\end{tabular}

Source: Alcatel Thalés Research and Technology [22]

The parameters described in Table 4 are implemented, in order to establish the impact generated by the SOA current variation, considering that the reference manufacturer works with $150 \mathrm{~mA}$. The results obtained by modifying this parameter are displayed in Table 5. With these it was determined that the SOA amplifier is highly susceptible and dependent on the polarization current, since each mode responds with different optical monitoring parameters, so that the current ideal polarization is $162 \mathrm{~mA}$ for booster mode, $158 \mathrm{~mA}$ for pre-amplification and $126 \mathrm{~mA}$, in-line. Although a lower current is needed in-line, it is in pre-amplification where the best conditions with respect to OPMs are presented. However, in all three cases the received powers are within the sensitivity of the receiver so the signal will be recognized and will not present major inconveniences. In Figure 6 (a) and (b), the SOA current range in which a constant BER of 1e-40 and high quality factor is obtained, for pre-amplification is around $134 \mathrm{~mA}$ and $184 \mathrm{~mA}$, while in booster it is $152 \mathrm{~mA}$ to $168 \mathrm{~mA}$ and in line, 118 $\mathrm{mA}$ to $154 \mathrm{~mA}$. 
Table 5. Optical monitoring parameters for SOA with $4 \lambda \times 2.5$ Gbps.

\begin{tabular}{|c|c|c|c|c|c|c|c|c|}
\hline $\begin{array}{c}\text { Distance } \\
\text { [km] }\end{array}$ & $\begin{array}{c}\text { Channel } \\
\text { [THz] }\end{array}$ & $\begin{array}{c}\text { Current } \\
{[\mathrm{mA}]}\end{array}$ & BER & $\begin{array}{c}\text { Q Factor } \\
\text { [dB] }\end{array}$ & $\begin{array}{c}P_{\mathrm{Rx}} \\
{[\mathrm{dBm}]}\end{array}$ & $\begin{array}{c}\text { Jitter } \\
\text { [ns] }\end{array}$ & $\begin{array}{l}\text { OSNR }_{\text {IN }} \\
{[\mathrm{dB}]}\end{array}$ & $\begin{array}{l}\text { OSNR }_{\text {out }} \\
\text { [dB] }\end{array}$ \\
\hline \multicolumn{9}{|c|}{ Booster mode } \\
\hline & & 150 & $1.0 \mathrm{e}-38$ & 22.51 & -24.56 & 0.003 & 43.81 & 47.53 \\
\hline \multirow[t]{2}{*}{85} & 195.5 & 162 & $1 e-40$ & 27.26 & -23.17 & 0.002 & 43.81 & 47.71 \\
\hline & & 168 & $1.1 \mathrm{e}-23$ & 20.19 & -22.99 & 0.002 & 43.81 & 47.84 \\
\hline \multicolumn{9}{|c|}{ Pre-amplification mode } \\
\hline & & 150 & $1 e-40$ & 32.72 & -22.20 & 0.002 & 43.81 & 47.39 \\
\hline \multirow[t]{2}{*}{85} & 195.5 & 158 & $1 e-40$ & 35.22 & -19.64 & 0.001 & 43.81 & 47.40 \\
\hline & & 186 & $4.5 e-37$ & 22.91 & -11.09 & 0.0006 & 43.81 & 47.46 \\
\hline \multicolumn{9}{|c|}{ In-line mode } \\
\hline \multirow{3}{*}{85} & & 118 & $1 \mathrm{e}-27$ & 20.92 & -27.83 & 0.005 & 43.81 & 47.36 \\
\hline & 195.5 & 126 & $1 e-40$ & 26.37 & -22.27 & 0.002 & 43.81 & 47.40 \\
\hline & & 150 & $1 e-30$ & 21.44 & -9.71 & 0.001 & 43.81 & 47.73 \\
\hline
\end{tabular}

Source: own work

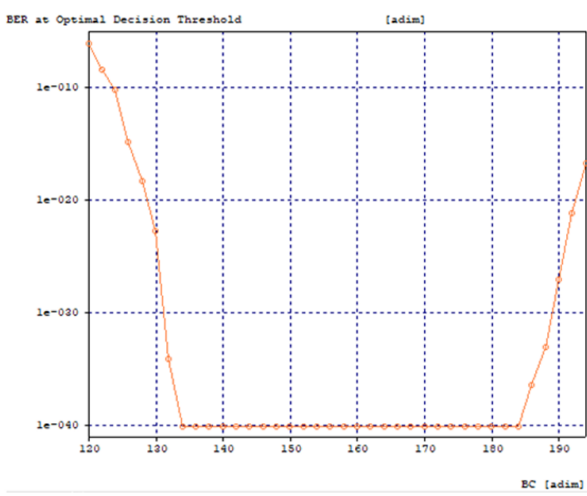

(a)

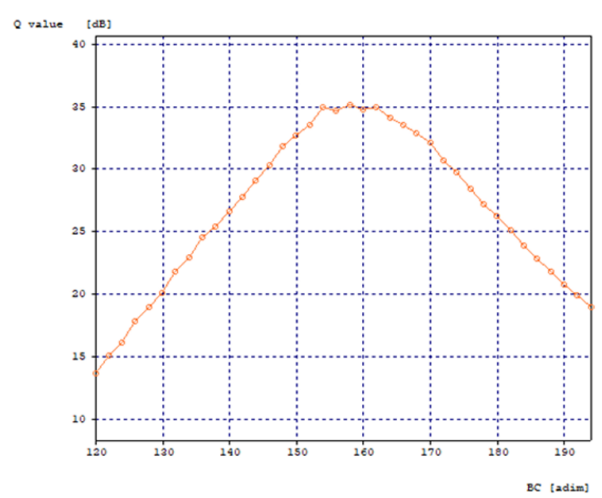

(b)

Figure 6. (a) BER vs. Bias Current (b) Q Factor vs. Bias current for SOA in preamplification with $4 \lambda \times 2.5 \mathrm{Gbps}$.

Source: own work

Also, the incidence in the optical output spectrum was verified, by varying the polarization current. With a low current, a phantom wave is produced with sufficient power to be detected by the receiver and when working with high currents, nonlinear phenomena such as FWM are stimulated, generating unwanted channels, even if the OPMs are not bad. Table 6 shows the ideal region where the SOA pumping source works in its three configurations, from which it is concluded that SOA in pre-amplification mode is the most robust system against FWM and OPM compared to SOA in booster and in-line. 
Table 6. Ideal region of SOA operation, in the $4 \lambda \times 2.5 \mathrm{Gbps}$ system.

\begin{tabular}{cccc}
\hline \multicolumn{2}{c}{ Power penalties for SOA } \\
\hline Configuration & Meets OPM objective & $\begin{array}{c}\text { Optical spectrum } \\
\text { without penalties [mA] }\end{array}$ & $\begin{array}{c}\text { Ideal Pumping } \\
\text { Region [mA] }\end{array}$ \\
\hline Booster & {$[136,170]$} & {$[0,138]$} & {$[136,138]$} \\
\hline Pre-amplification & {$[134,194]$} & {$[0,250]$} & {$[134,194]$} \\
\hline In-line & {$[118,154]$} & {$[0,126]$} & {$[118,126]$} \\
\hline
\end{tabular}

Source: own work

\subsection{EDFA amplifier}

Table 7 describes the parameters used in OptSim for the study of the EDFA amplifier, which belongs to a FIBERCORE device. This manufacturer makes possible the elaboration of high-performance and low-cost models for DWDM systems with a large number of channels, with characteristics such as constant absorption values of erbium-doped fiber, low insertion losses of the amplifier's internal components, these being, determining aspects for the optimal performance of an EDFA. As for the properties of the pumping source, it is designed with a forward pumping configuration or co-propagated.

Table 7. Physical model EDFA parameters

\begin{tabular}{cc}
\hline \multicolumn{2}{c}{ PARAMETERS } \\
\hline Signal wavelength $[\mathrm{nm}]$ & 1529 a 1559 \\
\hline Doped fiber length with erbium $[\mathrm{m}]$ & 16 \\
\hline Pump power $[\mathrm{mW}]$ & 115 \\
\hline Pump frequency $[\mathrm{nm}]$ & 977.1 \\
\hline Input/output Insertion loss $[\mathrm{dB}]$ & $\leq 1.35$ \\
\hline
\end{tabular}

Source: FIBERCORE [23]

In this case, for each mode the frequency and direction of pumping was first varied. It was found that better performance is achieved due to the quality of the received signal, with a $980 \mathrm{~nm}$ co-propagated pumping source for pre-amplification and in-line modes, and a $980 \mathrm{~nm}$ bidirectional source for booster. In Table 8, the results of the OPM are found by varying the power for the ideal pump configuration in each mode, where it can be noted that the ideal value of pumping power is $28 \mathrm{dBm}$ for pre-amplification and $12 \mathrm{dBm}$ for booster and in-line. Although all three have an ideal 
error rate (1e-40), high OSNR and power received within the sensitivity threshold, the best mode is in-line, having a higher quality factor than the others. In addition, this configuration has a region greater than the EDFA booster, in which there is a constant error rate of $1 e-40$ and high $\mathrm{Q}$ factor with a non-significant variation in that range, which is from $4 \mathrm{dBm}$ to $20 \mathrm{dBm}$ as shown in Figure 7 (a) and (b). It should be noted that the BER is ideal from $4 \mathrm{dBm}$ to $16 \mathrm{dBm}$ for booster and for pre-amplification from $3 \mathrm{dBm}$, because it is a robust system that maintains good performance, even if its conditions change, although it doesn't achieve such a high quality factor in this configuration.

Table 8. Optical monitoring parameters for EDFA with $4 \lambda \times 2.5$ Gbps.

\begin{tabular}{|c|c|c|c|c|c|c|c|c|}
\hline $\begin{array}{c}\text { Distance } \\
{[\mathrm{km}]}\end{array}$ & $\begin{array}{c}\text { Channel } \\
\text { [THz] }\end{array}$ & $\begin{array}{l}\text { Power } \\
\text { [dBm] }\end{array}$ & BER & $\begin{array}{c}\text { Q Factor } \\
\text { [dB] }\end{array}$ & $\begin{array}{c}\mathbf{P}_{\mathrm{Rx}} \\
{[\mathrm{dBm}]}\end{array}$ & $\begin{array}{c}\text { Jitter } \\
\text { [ns] }\end{array}$ & $\begin{array}{c}\text { OSNR }_{\text {IN }} \\
{[\mathrm{dB}]}\end{array}$ & $\begin{array}{l}\text { OSNR } \\
\text { [dB] }\end{array}$ \\
\hline \multicolumn{9}{|c|}{ Booster mode with $980 \mathrm{~nm}$ bidirectional pumping } \\
\hline & & 4 & $1 e-40$ & 27.41 & -24.77 & 0.0032 & 43.81 & 47.40 \\
\hline \multirow[t]{2}{*}{85} & 195.5 & 12 & $1 e-40$ & 38.60 & -15.50 & 0.0008 & 43.81 & 47.98 \\
\hline & & 20 & $1.5 \mathrm{e}-15$ & 17.86 & -14.36 & 0.0015 & 43.81 & 47.75 \\
\hline \multicolumn{9}{|c|}{ Pre-amplification mode with $980 \mathrm{~nm}$ co-pumping } \\
\hline \multirow{3}{*}{85} & & 20 & $1 e-40$ & 28.33 & 4.91 & 0.0009 & 43.81 & 47.41 \\
\hline & 195.5 & 28 & $1 e-40$ & 29.13 & 13.07 & 0.0008 & 43.81 & 47.41 \\
\hline & & 32 & $1 \mathrm{e}-40$ & 28.23 & 17.09 & 0.0009 & 43.81 & 47.43 \\
\hline \multicolumn{9}{|c|}{ In-line mode with $980 \mathrm{~nm}$ co-pumping } \\
\hline \multirow{3}{*}{85} & & 4 & $1 \mathrm{e}-40$ & 31.94 & -14.22 & 0.0007 & 43.81 & 47.29 \\
\hline & 195.5 & 12 & $1 \mathrm{e}-40$ & 39.89 & -1.20 & 0.0006 & 43.81 & 47.62 \\
\hline & & 20 & $1 e-40$ & 28.67 & 4.20 & 0.0007 & 43.81 & 47.24 \\
\hline
\end{tabular}

Source: own work 


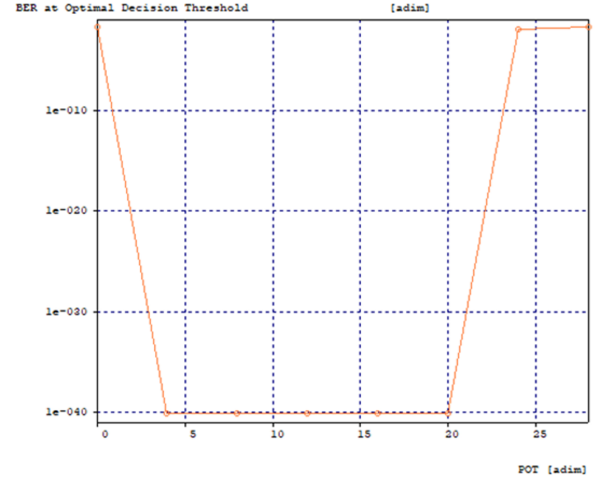

(a)

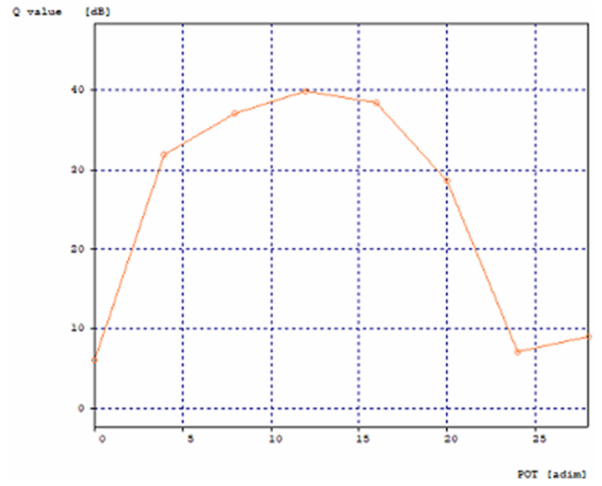

(b)

Figure 7. (a) BER vs. Pumping power (b) Factor Q vs. Pumping power for EDFA in line with $4 \lambda \times 2.5 \mathrm{Gbps}$ and $980 \mathrm{~nm}$ co-propagated pumping.

Source: own work

In Table 9, the ideal region in which the amplifier can operate is determined without degradation, taking into account both the monitoring parameters and the effect of the non-linear phenomenon FWM on the optical output spectrum. For low pumping powers there are no deformations in the spectrum, however, OPMs are not good, while OPMs improve in high pumping powers, although in this case the presence of new aggregate channels is evident. In pre-amplification, the power range in which the optical spectrum does not present penalties is equivalent to lower values of the maximum simulated value in OptSim, because, in this configuration, the system is highly tolerable to non-linearities and it is not possible to visualize the effect of the FWM, although the power continues to increase.

Table 9. Ideal region of EDFA operation, in $4 \lambda \times 2.5 \mathrm{Gbps}$ system.

\begin{tabular}{cccc}
\hline \multicolumn{4}{c}{ Power penalties for EDFA } \\
\hline Configuration & Meets OPM objective & $\begin{array}{c}\text { Optical spectrum } \\
\text { without penalties [dBm] }\end{array}$ & $\begin{array}{c}\text { Ideal Pumping } \\
\text { Region [dBm] }\end{array}$ \\
\hline Booster & {$[4,20]$} & {$[0,8]$} & {$[4,8]$} \\
\hline Pre-amplification & $\geq 3$ & $\leq 35$ & $\geq 3$ \\
\hline In-line & {$[4,20]$} & {$[0,12]$} & {$[4,12]$} \\
\hline
\end{tabular}

Source: own work 


\subsection{RFA amplifier}

Within the RFA investigated, two types are highlighted according to their design: LRA and DRA. Although both require the same parameters for simulation, some of their values differ, as shown in Table 10. In the case of discrete, it was used as a reference for the manufacturer Optilab, which offers a Raman amplifier of high efficiency and low power consumption for long distance DWDM networks. In the case of distributed, parameters defined by the CISCO manufacturer that presents a high-power Raman amplifier operating in the $\mathrm{C}$ band of the optical spectrum were considered.

Table 10. RFA parameters

\begin{tabular}{ccc}
\hline PARAMETERS & LRA & DRA \\
\hline Signal wavelength $[\mathrm{nm}]$ & 1530 to 1565 & 1500 to 1567 \\
\hline Pump power $[\mathrm{mW}]$ & 400 & 1000 \\
\hline Pump frequency $[\mathrm{nm}]$ & 1420 and 1455 & 1428 and 1457 \\
\hline Operating temperature $\left[{ }^{\circ} \mathrm{k}\right]$ & 273 & 273 \\
\hline Pump attenuation $[\mathrm{dB}]$ & 0.2 & 0.2 \\
\hline
\end{tabular}

Source: Optilab [24] and CISCO [25]

\subsubsection{LRA amplifier}

With this amplification, although with bidirectional pumping, less power is required to achieve good performance. The best performance is obtained with a $1455 \mathrm{~nm}$ counter-propagation source for booster and in-line, while for pre-amplification is achieved with a co-propagated pump of $1420 \mathrm{~nm}$. Table 11 shows the OPM by varying the power when the direction and frequency of pumping is ideal in the different amplification modes, and it can be seen that the best pre-amplification behavior is achieved with $35 \mathrm{dBm}$. Meanwhile, with booster and in line with $32 \mathrm{dBm}$, better system quality in-line and therefore the best performance of the three is obtained. In this mode there is an ideal BER region (1e-40) that is between $25 \mathrm{dBm}$ and $35 \mathrm{dBm}$ as seen in Figure 8 (a) and (b).

On the other hand, for booster, this region is from $30 \mathrm{dBm}$ and $34 \mathrm{dBm}$, and for pre-amplification, from $31 \mathrm{dBm}$, therefore, it is also recommended to work with LRA because it requires less power compared to the other modes. 
Table 11. Optical monitoring parameters for LRA with $4 \lambda \times 2.5 \mathrm{Gbps}$.

\begin{tabular}{|c|c|c|c|c|c|c|c|c|}
\hline $\begin{array}{c}\text { Distance } \\
\text { [km] }\end{array}$ & $\begin{array}{c}\text { Channel } \\
\text { [THz] }\end{array}$ & $\begin{array}{l}\text { Power } \\
{[\mathrm{dBm}]}\end{array}$ & BER & $\begin{array}{c}\text { Q Factor } \\
\text { [dB] }\end{array}$ & $\begin{array}{c}P_{R x} \\
{[d B m]}\end{array}$ & $\begin{array}{c}\text { Jitter } \\
\text { [ns] }\end{array}$ & $\begin{array}{l}\text { OSNR }_{\mathrm{IN}} \\
{[\mathrm{dB}]}\end{array}$ & $\begin{array}{l}\text { OSNR } \\
\text { [dB] }\end{array}$ \\
\hline \multicolumn{9}{|c|}{ Booster mode with 1455 nm counter-pumping } \\
\hline & & 26 & $1.3 e-8$ & 14.91 & -31.19 & 0.008 & 43.81 & 47.11 \\
\hline \multirow[t]{2}{*}{85} & 195.5 & 32 & $1 e-40$ & 37.65 & -18.42 & 0.001 & 43.81 & 47.55 \\
\hline & & 38 & 0.0018 & 9.89 & -13.36 & 0.0069 & 43.81 & 46.93 \\
\hline \multicolumn{9}{|c|}{ Pre-amplification mode with $1420 \mathrm{~nm}$ co-pumping } \\
\hline \multirow{3}{*}{85} & & 27 & $4.3 e-5$ & 11.91 & -32.80 & 0.0119 & 43.81 & 47.04 \\
\hline & 195.5 & 35 & $1 e-40$ & 30.04 & -15.23 & 0.0011 & 43.81 & 47.09 \\
\hline & & 37 & $1 \mathrm{e}-40$ & 29.72 & -3.63 & 0.0011 & 43.81 & 47.06 \\
\hline \multicolumn{9}{|c|}{ In-line mode with $1455 \mathrm{~nm}$ counter-pumping } \\
\hline \multirow{3}{*}{85} & & 26 & $1.0 \mathrm{e}-31$ & 21.49 & -27.67 & 0.0051 & 43.81 & 48.42 \\
\hline & 195.5 & 32 & $1 \mathrm{e}-40$ & 39.07 & -1.16 & 0.0007 & 43.81 & 48.94 \\
\hline & & 36 & 0.0055 & 8.35 & 5.19 & 0.0093 & 43.81 & 48.16 \\
\hline
\end{tabular}

Source: own work

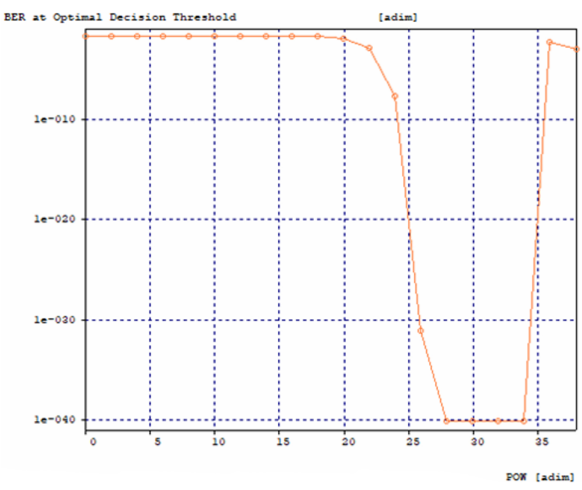

(a)

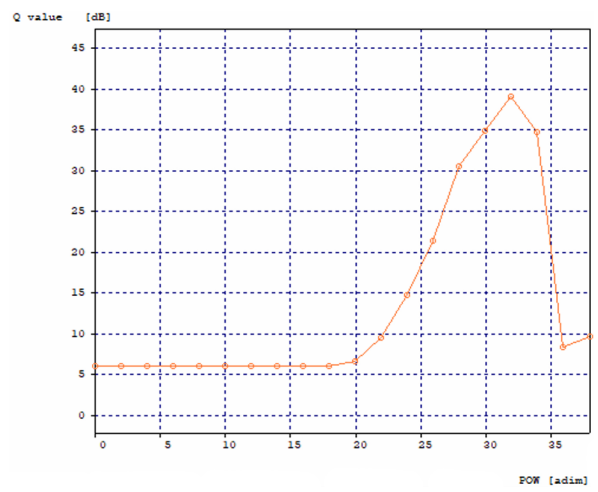

(b)

Figure 8. (a) BER vs. Pumping power (b) Factor $Q$ vs. Pumping power for LRA in line with $4 \lambda \times 2.5 \mathrm{Gbps}$ and counter-propagated pumping of $1455 \mathrm{~nm}$.

Source: own work

From Table 12, it is concluded that for a system with 4 channels at 2.5 Gbps, using a discrete Raman amplification, the configuration that presents a better performance at the OPM level and power penalties is the in-line mode with a direction and frequency of pumping in counter-propagation of $1455 \mathrm{~nm}$ with an ideal pumping of $32 \mathrm{dBm}$, which presents a robust system that is less sensitive to power variations compared to the other configurations. As for the power penalties generated by the non-linear FWM effect, in line for a power below the ideal range, the signal does not 
have good OPMs, but does not present non-linearities, and at the ideal value of the previous analysis (32 dBm), additional channels begin to be generated, although they are not detected by the receiver until $36 \mathrm{dBm}$.

Table 12. Ideal region of operation of the LRA, in $4 \lambda \times 2.5$ Gbps system.

\begin{tabular}{cccc}
\hline \multicolumn{4}{c}{ Power penalties for LRA } \\
\hline Configuration & Meets OPM objective & $\begin{array}{c}\text { Optical spectrum without } \\
\text { penalties [dBm] }\end{array}$ & $\begin{array}{c}\text { Ideal Pumping } \\
\text { Region [dBm] }\end{array}$ \\
\hline Booster & {$[28,38]$} & {$[0,30]$} & {$[28,30]$} \\
\hline Pre-amplification & $>31$ & $<37$ & $>31$ \\
\hline In-line & {$[26,36]$} & {$[0,30]$} & {$[26,30]$} \\
\hline
\end{tabular}

Source: own work

\subsubsection{DRA amplifier}

The analysis of this amplifier is carried out considering the same variables as LRA, direction, frequency and pumping power, except for the amplification modes, since in this case it is not possible. It was noted that, in both pumping frequencies, the best condition is obtained with bidirectional pumping, with an ideal BER and quality factor, in addition to the received power remaining within the sensitivity range.

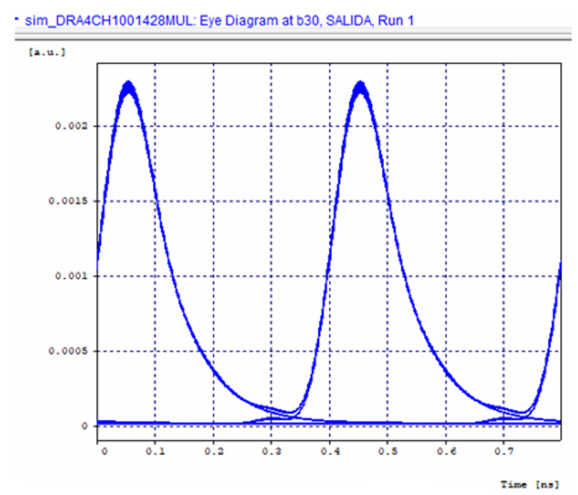

(a)

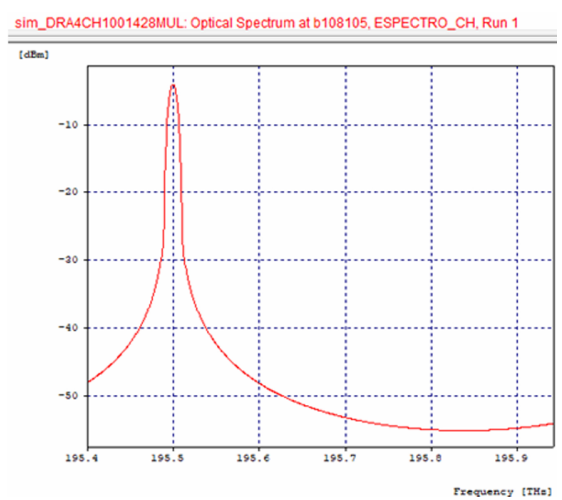

(b)

Figure 9. (a) Eye diagram (b) Optical Spectrum for DRA with $4 \lambda \times 2.5$ Gbps for a bidirectional source of $1428 \mathrm{~nm}$ and power of $34.7 \mathrm{dBm}$.

Source: own work 
Table 13. OPM for DRA with $4 \lambda \times 2.5 \mathrm{Gbps}$ and pumping of $1428 \mathrm{~nm}$.

\begin{tabular}{|c|c|c|c|c|c|c|c|c|}
\hline $\begin{array}{c}\text { Distance } \\
\text { [km] }\end{array}$ & $\begin{array}{c}\text { Channel } \\
\text { [THz] }\end{array}$ & $\begin{array}{l}\text { Power } \\
\text { [dBm] }\end{array}$ & BER & $\begin{array}{c}\text { Q Factor } \\
\text { [dB] }\end{array}$ & $P_{\mathrm{Rx}}[\mathrm{dBm}]$ & Jitter [ns] & $\begin{array}{l}\text { OSNR }_{\text {IN }} \\
{[\mathrm{dB}]}\end{array}$ & $\begin{array}{l}\text { OSNR }_{\text {out }} \\
\text { [dB] }\end{array}$ \\
\hline \multicolumn{9}{|c|}{ Co-pumping } \\
\hline & & 26 & $4.7 e-7$ & 13.90 & -31.96 & 0.0098 & 43.81 & 47.32 \\
\hline \multirow[t]{2}{*}{85} & 195.5 & 30 & $1.1 \mathrm{e}-30$ & 21.22 & -28.20 & 0.0051 & 43.81 & 47.33 \\
\hline & & 34 & $1 \mathrm{e}-40$ & 38.25 & -18.74 & 0.0012 & 43.81 & 47.44 \\
\hline \multicolumn{9}{|c|}{ Counter-pumping } \\
\hline \multirow{3}{*}{85} & & 30 & $3.8 \mathrm{e}-26$ & 20.64 & -28.18 & 0.0052 & 43.81 & 47.35 \\
\hline & 195.5 & 36 & $1 \mathrm{e}-40$ & 31.09 & -9.58 & 0.0007 & 43.81 & 47.27 \\
\hline & & 39 & $5.3 e-16$ & 18.33 & 9.25 & 0.0026 & 43.81 & 47.35 \\
\hline \multicolumn{9}{|c|}{ Bidirectional pumping } \\
\hline \multirow{3}{*}{85} & & 30 & $1 \mathrm{e}-40$ & 31.55 & -22.02 & 0.0020 & 43.81 & 47.35 \\
\hline & 195.5 & 34.7 & $1 \mathrm{e}-40$ & 40.00 & -4.03 & 0.0001 & 43.81 & 47.44 \\
\hline & & 36 & $1 \mathrm{e}-40$ & 39.27 & -1.91 & 0 & 43.81 & 47.49 \\
\hline
\end{tabular}

Source: own work

It is observed that the best system behavior is obtained when the power is 34.7 $\mathrm{dBm}$ for a frequency of $1428 \mathrm{~nm}$ with a bidirectional source as seen in Table 13. On the other hand, if the source is co-propagated, $34 \mathrm{dBm}$ is required to achieve the best performance and if it is counter-propagated, a greater power, $36 \mathrm{dBm}$, is required. Figure 9 (a) and (b) shows the eye and optical spectrum diagram, which shows the behavior of the amplifier with an ideal error rate, without the presence of degradations or phase deviation in the eye diagram.

Table 14. Ideal region of operation of the DRA, in $4 \lambda \times 2.5 \mathrm{Gbps}$ system.

\begin{tabular}{cccc}
\hline \multicolumn{4}{c}{ Power penalties for DRA } \\
\hline Configuration & $\begin{array}{c}\text { Meets OPM } \\
\text { objective }\end{array}$ & $\begin{array}{c}\text { Optical spectrum without } \\
\text { penalties [dBm] }\end{array}$ & $\begin{array}{c}\text { Ideal Pumping } \\
\text { Region [dBm] }\end{array}$ \\
\hline Counter with $\mathbf{1 4 2 8} \mathbf{~ n m}$ & {$[30,39]$} & {$[0,38]$} & {$[30,38]$} \\
\hline Co with $\mathbf{1 4 5 7} \mathbf{~ n m}$ & {$[32,36]$} & {$[0,34]$} & {$[32,34]$} \\
\hline Bi with $\mathbf{1 4 2 8} \mathbf{~ n m}$ & {$[30,36]$} & {$[0,34.7]$} & {$[30,34.7]$} \\
\hline
\end{tabular}

Source: own work

Table 14 determined the ideal region in which the DRA amplifier works without any penalties, taking into account the shape of the output spectra and the optical monitoring parameters. For counter-propagation, the ideal region will be from $30 \mathrm{dBm}$ to values less than $38 \mathrm{dBm}$, for co-propagation, power greater than or equal to $30 \mathrm{dBm}$ 
up to $34 \mathrm{dBm}$ and for bidirectional, values greater than $30 \mathrm{dBm}$ and less than or equal to $34.7 \mathrm{dBm}$; the latter being the best option, since it has an ideal pumping of 34.7 $\mathrm{dBm}$, where it has an ideal behavior with a BER of 1e-40 and a quality factor of $40 \mathrm{~dB}$.

\subsubsection{Comparative analysis of optical amplifiers}

Next, a synthesis with the simulation level performance of the simulated optical amplifiers is presented, where it is evident that, although for each amplification system a different ideal mode and pumping was found, a robust network is generally guaranteed with these configurations, with high performance and that allows for long propagation distances without exceeding power limits that degrade the signal.

Table 15 shows that the semiconductor optical amplifier is quite susceptible to variations in its design parameters. Sensitivity with respect to polarization and changes in its physical parameters cause changes in the performance of the optical link. The system with EDFA amplification can reach great distances with low pumping power and without significantly deteriorating the signal, while the RFA requires more power to reach larger distances. However, with LRA it is possible to reach longer distances without the signal degrading to the point of not being detected by the receiver.

In general, the parameter with the greatest influence on excitation of nonlinearities is the polarization current for SOA and pumping power for EDFA and RFA. In values below the ideal working range of the amplifiers, there are very low power levels that do not allow any channel to be detected and in higher values, power penalties are excited due to FWM. As for the commercial cost of the analyzed amplifiers, the one with the highest value is the RFA, especially if it is DRA, since this achieves the amplification effect thanks to the same fiber used for signal transmission. 
Table 15. Table with synthesis of amplifier performance results

\begin{tabular}{|c|c|c|c|c|}
\hline & \multirow{2}{*}{ SOA } & \multirow{2}{*}{ EDFA } & \multicolumn{2}{|c|}{ RFA } \\
\hline & & & LRA & DRA \\
\hline Ideal mode & Pre-amplification & In-line & In-line & Doesn't apply \\
\hline Ideal pumping & $158 \mathrm{~mA}$ & $\begin{array}{l}\text { Co-propagated of } \\
980 \mathrm{~nm} \text { and } 12 \mathrm{dBm}\end{array}$ & $\begin{array}{c}\text { Counter-propagated } \\
\text { of } 1455 \mathrm{~nm} \text { and } \\
32 \mathrm{dBm}\end{array}$ & $\begin{array}{l}\text { Bidirectional of } \\
1428 \mathrm{~nm} \text { and } \\
34.7 \mathrm{dBm}\end{array}$ \\
\hline $\begin{array}{l}\text { Eye diagram for } \\
\qquad 85 \mathrm{~km}\end{array}$ & $=\sqrt{ }$ & 1 & 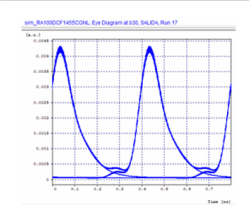 & A \\
\hline Optical spectrum & (N) & (n) & And An An & , \\
\hline Power penalties & Highly susceptible & $\begin{array}{l}\text { Moderately } \\
\text { susceptible }\end{array}$ & Not very susceptible & Not very susceptible \\
\hline Cost & Low & Medium & High & High \\
\hline Performance & Good & Good & Good & Very Good \\
\hline $\begin{array}{c}\text { Maximum } \\
\text { distance reached }\end{array}$ & Good (125 km) & $\begin{array}{l}\text { Very Good } \\
(195 \mathrm{~km})\end{array}$ & $\begin{array}{l}\text { Very Good } \\
(215 \mathrm{~km})\end{array}$ & Good (116 km) \\
\hline
\end{tabular}

Source: own work

\section{DISCUSSION AND CONCLUSIONS}

In this article, the performance analysis of different optical amplifiers was performed for a DWDM / XGS-PON network environment compared to devices that are on the market, with respect to the power penalties produced by the non-linear FWM phenomenon. The discussion and conclusions regarding the most important aspects of the research work carried out are presented below.

\subsection{Discussion}

Of the different works related to the topics covered in this research, it should be noted that the authors in [1] evaluated the performance of a DWDM network with EDFA amplification according to parameters such as gain and noise, while in this work these parameters are not estimated and two other types of amplification are also analyzed by varying the pumping parameters only, and not the power input, spacing between channels, EDFA length and erbium concentration. 
The main focus of Gomez and Grijalba [2] was to analyze the performance of a WDM network by using different modulation formats, determining the effects of linear and non-linear phenomena in the system, including FWM which is the one seen in our research. By exciting this nonlinearity by varying the pumping of the amplifier, the results agree with [4], where Ramaswami, Sivajaran and Sasaki say that optical degradations lead to an increase in the power received in order to compensate and obtain the same error rate as an ideal system.

In the work development, a comparative analysis of SOA, EDFA and RAMAN optical amplifiers was presented in a manner similar to [5], with the difference that Singh and Kaler evaluated the performance with respect to dispersion, in a 10 Gbps WDM system with more than 16 channels. Similarly, Torres [6] made a comparison of the performance of EDFA and SOA amplifiers, but identifying the advantages and disadvantages offered by these devices in pulsed operation modes and with multiple wavelengths.

Our work contributes to the review article by Castro [9] about DWDM systems that use RAMAN amplification, in which linear, nonlinear phenomena, OPMs are defined and it is indicated that considerably increasing the power required by the pumping source, raises the general level of intensity, giving rise to a greater influence of non-linear effects that degrade the signal, which could be corroborated with the analysis of the results of our research.

With this research work it was found that the performance of a DWDM XGSPON system is considerably affected by varying the design parameters of the optical amplifiers in addition to the amplification mode, which was highlighted by Putrina, Olonkis, Bobrovs and Ivanovs in [11]. Finally, the authors of [13] demonstrated that it is possible to implement and evaluate performance in an XGS-PON / GPON network architecture, which was not considered in our research, but it is important to consider for future work due to the advantages and flexibility that this offers.

\subsection{Conclusions}

From the results obtained, the performance of the different optical amplifiers in the three amplification modes, compared to the power penalties, was evaluated to determine which of the configurations provides advantages to be implemented in optical networks.

It was found that, of the amplifiers studied, it is advisable to use SOA for short distances, since it generates a good cost-efficiency ratio for links less than $85 \mathrm{~km}$. If a metropolitan or long-range network is required, it is advisable to use EDFA, LRA or 
DRA, considering that although DRA is more attractive because it needs less elements in the network since it is a fiber with amplification, it is commercially much more expensive than implementing an EDFA amplifier on a fiber optic link.

However, it is important to take into account the power penalties that occur due to non-linear effects, due to its strong relationship with the variation of the amplifier's pumping parameters, since, if the device is highly susceptible to the penalties, this can significantly influence the performance of the network.

Therefore, it should be considered that increasing the pumping power or current of the amplifier makes the effect of non-linearities more evident, resulting in an increase in the bit error rate, distortion of the eye diagram, and the presence of new channels, since it is FWM. Also, in some cases, when working with the amplifiers in their maximum performance or ideal value according to optical monitoring parameters, instead of achieving a significant improvement in the quality of the signal received, it would be exciting power penalties.

Otherwise, the results obtained from the simulated optical amplifiers under the characteristics of real devices, verify that these parameters can vary according to the needs of the network, because in most scenarios they do not correspond to the best performance and even excite power penalties.

This research project, leaves some network characteristics that can be taken as a reference when working with optical amplifiers and their different modes studied in ideal power regions without manifesting second-order degradations.

\section{ACKNOWLEDGMENTS}

The authors express their gratitude to the telecommunications department of the Faculty of Electronics and Telecommunications Engineering of the Universidad del Cauca for their contributions and recommendations, to the GNTT research group New Telecommunications Technologies Group of the Universidad del Cauca for their collaboration and advice on the development of this article.

\section{REFERENCES}

[1] M. ul zaman, S. Iqbaly Isha, "Performance analysis of EDFA amplifier for DWDM system," in 2014 International Conference on Computing for Sustainable Global Development (INDIACom), New Delhi, 2014, pp. 840-843. [Online]. doi: 10.1109/IndiaCom.2014.6828081 
[2] J. F. Grijalba y G. A. Gómez, "Análisis del Desempeño de Formatos de Modulación en Comunicaciones Ópticas sobre Redes WDM," Universidad del Cauca, Tesis de pregrado, 2010, pp. 1-18. Available: Biblioteca Jose María Serrano, Universidad del Cauca

[3] ITU-T Rec. G.697, Optical monitoring for dense wavelength division multiplexing systems, 2016, pp. 5-10. [Online]. Available: https://www.itu.int/rec/T-REC-G.697/es

[4] R. Ramaswami y K. N. Sivajaran, Optical Networks. A pratical perspective, 3rd ed. San Francisco: Morgan Kaufmann Publishers, 2002, pp. 290-292. [Online]. Available: http://www.cesarkallas. net/arquivos/faculdade-pos/TP319-redes-opticas/Optical-Networks-3nd.pdf

[5] S. Singh, A. Singh, R.S. Kaler, "Performance evaluation of EDFA, RAMAN and SOA optical amplifier for WDM systems," Optik, vol. 124, no. 2, pp. 95-101, 2013. [Online]. doi: https://doi. org/10.1016/j.ijleo.2011.11.043

[6] M. Á. Yépez Torres, "Sistemas láser con amplificadores semiconductores y de fibra óptica," Universidad Nacional Autónoma de México, Tesis de pregrado, 2012, pp. 62-67. [Online]. Available: http://www.ptolomeo.unam.mx:8080/xmlui/

[7] ITU-T Rec. G.661, Definitions and test methods for the relevant generic parameters of optical amplifier devices and subsystems, 2007, pp. 18-20. [Online]. Available: https://www.itu.int/ rec/T-REC-G.661/es

[8] ITU-T Rec. G.663, Application-related aspects of optical amplifier devices and subsystems, 2011, pp. 34-35. [Online]. Available: https://www.itu.int/rec/T-REC-G.663/es

[9] G. A. Muñoz Castro, "DWDM Networks When Using Raman Configurations with DCF Fibers," Sist. y Telemática, vol. 15, no. 41, pp. 27-43, 2017. [Online]. doi: https://doi.org/10.18046/syt. v15i41.2454

[10] ITU-T Rec. G.665, Características generales de los amplificadores Raman y de los subsistemas con amplificación Raman, 2005, pp. 2-3. [Online]. Available: https://www.itu.int/ rec/T-REC-G.665/es

[11] J. Putrina, S. Olonkins, V. Bobrovs y G. Ivanovs, "Comparison of discrete and distributed in-line Raman amplifiers in a 16 channel DWDM transmission system," in 2017 Progress in Electromagnetics Research Symposium - Fall (PIERS - FALL), Singapore, 2017, pp. 236-241. [Online]. doi: 10.1109/PIERS-FALL.2017.8293141 
[12] ITU-T Rec. G.662, Características genéricas de los dispositivos y subsistemas de amplificadores ópticos, 2005, pp. 2-6. [Online]. Available: https://www.itu.int/rec/T-REC-G.662/es

[13] K. A. Mat Sharif, N. A Ngah, A. Ahmad, K. Khairi, Z. A. Manaf y D. Tarsono, "Demonstration of XGS-PON and GPON Co-Existing in the Same Passive Optical Network," in 2018 IEEE 7th International Conference on Photonics (ICP), Kuah, 2018, pp. 1-3. [Online]. doi: 10.1109/ ICP.2018.8533167

[14] ITU-T Rec. G.9807.1, 10-Gigabit-capable symmetric passive optical network (XGS-PON), 2016, pp. 24-49. [Online]. Available: https://www.itu.int/rec/T-REC-G.9807.1/es

[15] SYNOPSYS, OptSim Product Overview, 2019. [Online]. Available: https://www.synopsys.com/ optical-solutions/rsoft/system-network-optsim.html

[16] R. S. Pressman, Ingeniería del Software, un enfoque práctico, 7th ed. Madrid: McGraw-Hill, 2001, pp. 33-34. [Online]. Available: http://cotana.informatica.edu.bo/downloads/Id-Ingenieria.de.software.enfoque.practico.7ed.Pressman.PDF

[17] Universitat Politéctnica de Catalunya, OPNET: Manual de usuario, Barcelona, 2004, pp. 12-13. [Online]. Available: http://ansat.es/soporte/docs/fragmentacion/OPNET_Modeler_ Manual.pdf

[18] E. Villalba Domínguez y E. Y. Ramón Martínez, Desarrollo de sistemas con metodología RUP (Rational Unified Process), Facultad de Ingeniería, Universidad Nacional Autónoma de México (UNAM), Tesis de pregrado, 2012, pp. 113- 130. [Online]. doi: http://132.248.52.100:8080/ xmlui/handle/132.248.52.100/175

[19] ITU-T Rec. G. 694, Spectral grids for WDM applications: DWDM frequency grid, 2012, pp. 2-5. [Online]. Available: https://www.itu.int/rec/T-REC-G.694.1/es

[20] ITU-T Rec. G.698.1, Aplicaciones multicanal de multiplexación por división en longitud de onda densa con interfaces ópticas monocanal, 2009, pp. 10-16. [Online]. Available: https://www.itu. int/rec/T-REC-G.698.1/es

[21] ITU-T Rec. G.Sup39, Optical system design and engineering considerations, 2016, pp. 56-58. [Online]. Available: https://www.itu.int/rec/T-REC-G.Sup39/en

[22] Alcatel Thalés Research and Technology, 10G SOA, 2016. [Online]. Available: http://www.35lab.fr/ 
[23] Fibercore, Product Factnote IsoGain, 2015. [Online]. Available: https://www.fibercore.com/ product/erbium-doped-fiber-isogain

[24] Optilab, 5 Channels Raman Laser Source, Rackmount, 2016. [Online]. Available: http://legacy.optilab.com/products/category/Raman_Amplifier/5_Channels_Raman_Laser_Source_ Rackmount/

[25] CISCO, Cisco ONS 15454 MSTP High-Power CounterPropagating and Co-Propagating Raman Amplifiers, 2012. [Online]. Available: https://www.cisco.com/c/en/us/products/collateral/ optical-networking/ons-15454-series-multiservice-provisioning-platforms/data_sheet_c78658538.html 